\title{
What Makes Radio Listening Clubs as a Participatory Communication for Development Platform Work? A Case Study of Monkey Bay, Malawi
}

\section{Levi Zeleza Manda, University of Malawi, Malawi}

\begin{abstract}
This case study used qualitative ethnographic research methods, notably focus group discussions, Most Significant Change (MSC) narratives, and key informant interviews, to investigate drivers and the impact of Radio Listening Clubs (RLCs) as a participatory communication platform for development in Malawi. It concludes that personal commitment and innovativeness of members are the key drivers of RLC success. Radio Listening Clubs whose members are active, innovative and committed are more impactful than those clubs whose members are passive and uncommitted to the objectives of the RLC. Since emerging evidence indicates that the RLC platform is an effective development and critical empowerment tool, the study recommends that radio-based communication for development interventions should be accompanied by some form of RLC or community conversation platform to ensure fruitful exchanges among duty bearers, community members, and the media. Radio Listening Club establishment should be preceded by a community readiness assessment to embrace the tool to avoid resource wastage.
\end{abstract}

Keywords: participation, radio listening clubs, RLC, radio listening committees, radio forums, communication effects 


\section{Introduction}

Panos Southern Africa (PSAf) has been instrumental in using public and community media to advance social development in Southern Africa by, inter alia, affording the poor and marginalised the tools and platforms with which to speak out against patriarchal traditions that suppress women and children, to demand and set the their own agenda for social development, to track resources meant for local development and to hold elected leaders and other duty bearers accountable. One of the major and innovative communication methodologies PSAf has championed is the Radio Listening Club (RLC), a development through radio (DTR) communication platform, which comprises 15-40 people who meet regularly to identify, plan, discuss and record social issues that need immediate attention (PSAf, 2003; Moyo, 1991). According PSAf (n.d) the recordings are collected by a local RLC monitor or coordinator and sent to a partner-broadcasting house, such as a national broadcasting radio station or a community radio station, which, in turn, takes the questions and concerns of the clubs to appropriate experts or policy makers for answers. These experts respond to the concerns and are tape-recorded. Then the broadcasting house produces and broadcasts a full radio programme, juxtaposing the community's questions and concerns and the duty bearers' responses. The programs are usually in the local language. The RLC members meet to listen to and record the full broadcasts of their radio programmes. Later, the RLC meets again and discusses the programme's strengths and weaknesses, reviews the main lessons communicated and issues that require clarification or follow-up before tackling a different social issue. Thus, the RLC acts as a public sphere where unfettered dialogic communication between the local people and the duty bearers takes place.

Theoretically, the RLC enhances capacity of partner radio stations to assume their role as agents of social change and development (Figueroa et al. 2005). The figure below summarizes RLC methodology. 
Figure 1: The RLC Methodology

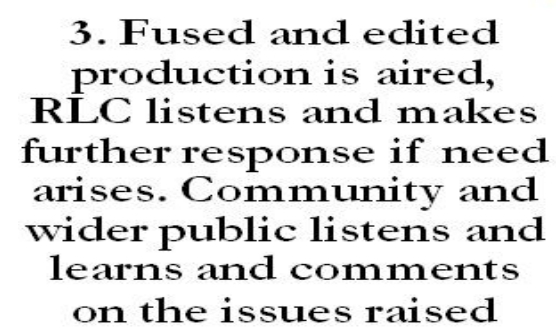

3. Fused and edited production is aired, RLC listens and makes further response if need arises. Community and wider public listens and

learns and comments

on the issues raised

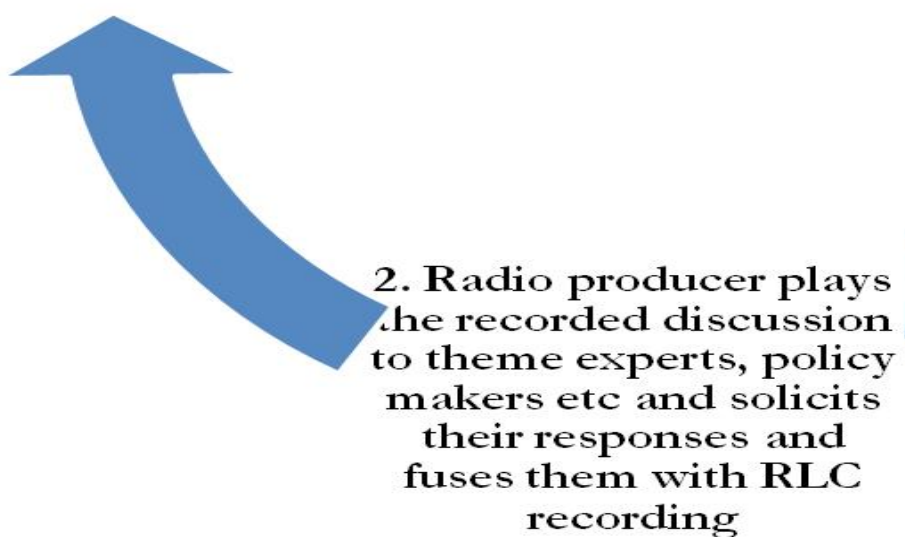

1. RLC meets weekly to discuss issues and record programme (using Tape, Mini disk or Flash Mike) and send recording to producer at radio station

\section{Source: http://www.panos.org.zm/content/psaf-methodologies}

It is clear from the above illustration that in practice, the term RLC is a misnomer because the clubs do more than listen to radio. As it will become clearer later in this article, the RLC members double as issue identifiers, news gatherers (reporters), sound editors, producers, and critical radio listeners (reviewers). The term RLC connotes passive listening. Hence, calling the RLC a community media club (CMC) would be more appropriate as this would take into account all media activities the club members engage in.

\section{Literature Review}

\section{The RLC as A Participatory Development for Development Platform}

Evidence is now emerging that the RLC methodology is a participatory communication platform that has the potential to catalyse poor societies into actions that could lead to sustainable social change and development. For instance, in the African Great Lakes countries of Rwanda, Burundi and the Democratic Republic of the Congo, the Women in Post Conflict Situations (WIPS) project used radio listening committees, as RLCs are termed in that area, and community conversations, and theatre for development to mitigate genderbased violence and create peace and trust between belligerent Tutsi and Hutu tribes-people in 
rural areas (Rasmussen, 2009; Danida, 2011). In their evaluations of the RLC implemented in Malawi and Zambia, Warnock (2001) and Banda (2006) conclude that the Radio Listening Club methodology helped to transform the lives of women in those sub-Saharan countries. The two evaluation reports indicate the women in Zambia and Malawi were empowered to challenge their domination by men in the home and in politics because the women were able to identify development issues that needed the attention of authorities. Economically, the women were able to take charge of their own income and decide what to do with it; and the women became self-confident and demystified "the microphone" because they carried out interviews and recorded their own radio programmes.

Also, Manyozo (2005; 2012) discusses how the use of RLCs empowered rural audiences in Malawi to demand services from the government without fear of reprisal while Makowa (2009) reports that the RLCs transformed farmers into researchers and innovators in areas targeted by the Story Workshop's Mwana Alirenji, a farmer-to-farmer magazine radio programme which was complemented by "radio research gardens". Chimala (2011) and Uladi (2011) present photographic evidence of infrastructure developments in the Nanjiri and Mbela areas of Malawi which resulted from RLC discussions associated with the Kanthu N'khama radio programme produced and broadcast by the Malawi Broadcasting Corporation (MBC). More recently, a Panos Southern Africa (PSAf) (2013) evaluation concluded that because of the RLC platform and methodology, rural communities in Malawi, Zambia and Mozambique were able to promote minority cultures and languages; track budget allocations and resources meant for local development; and produce culture-specific and relevant content for local radio stations. As a specific achievement, PSaf (2013) cites a radio program on the Usisya Community Radio Station in Nkhata Bay, Malawi, during which some community members questioned the rationale behind deploying two police officers to an area covering more than 10,000 square kilometres and hosting 30,000 people (UNESCO, 2010). In response, the Malawi Government increased the number of police officers to six (PSAf, 2013).

The above cases provide strong evidence that RLCs, as a participatory communication for development methodology and tool does lead to political empowerment, social transformation, and engender infrastructural development. However, what makes the RLC 
methodology and platform work has not been sufficiently explored, and that is what this study set out to understand.

\section{Research Objectives and Methodology}

The main objective of this study was to explore the drivers or factors and conditions that make the Radio Listening Club Methodology work. The study examined the RLCs founded by or attached to the Dzimwe Community Radio Station, which is located in the Monkey Bay area of Malawi. Specifically, this study sought to find out if RLCs had 1) brought development to their communities; 2) empowered communities and individual participants to demand services from duty bearers; 3 ) provided rural communities a platform to be heard and influence national development discourse, 4) stimulated debate on issues of communal and national interest, and 5) why the RLCs worked.

To achieve these, the study deployed a qualitative case study design. As Creswell (2003) and Stake (1995) note, a case study is the exploration of a bounded system. The system could be an individual, an idea, a programme, an issue or a geographical area (Yin, 1994 cited by Bell, 2007). In this study, Monkey Bay was geographic case, while the Radio Listening Clubs were the communication issue/methodology cases.

\section{Ethical Consideration}

Prior to interviews and focus group discussions, all the participants in the study were fully informed about the goal and aims, and the sponsors of the study. They were advised that they were free to participate or not or to stop the interview or discussion if they were not satisfied with the nature of the questions. Further, the participants were informed that their names would appear in an article that would be circulated worldwide. They signed or fingerprinted the consent form. As such, all names mentioned in this study have been used with the consent of the individual participants.

\section{Data Collection and Analysis}

The study employed ethnographic data gathering techniques; notably, personal observation, key informant interviews, Most Significant Change (MSC) narratives, and focus group discussions. The author conducted key informant interviews with two chiefs, two officials from an international development NGO, the radio producer responsible for RLCs at the 
Malawi Broadcasting Corporation (MBC), the Dzimwe Community Radio station manageress, and the coordinator of the Dzimwe Community Radio station RLCs coordinator. He also facilitated or moderated focus group discussions with three RLCs, one made up exclusively of boys/young men, and two made up of women only. Interviews and discussions were recorded and field notes were taken to ensure that nothing was lost in case of tape failure.

Data were analysed using qualitative approaches which different authors have given different names, but whose aim is to understand what the textual data mean and to make internal generalizations; which generalizations are different from external or universal laws that quantitative studies often aspire to generate (Bryman, 1988; Mouton, 1996). However, as Maxwell (1992 cited by Strelitz, 2002) argue, external generalizations (beyond the case study area) in qualitative studies are possible when a community is homogenous. Homogeneity here must be understood to include people who share general characteristics even if they are spread across large geographical areas. Thus, the Monkey Bay case studies findings can be generalized across marginalized Malawi and Zambia and Mozambique, whose people several characteristics. Qualitative data analysis, be it grounded theory (Bryman and Teevan, 2005) or analytic induction (Bryman and Teevan, 2005), thematisation, meaning categorization and interpretation (Kvale, 1996) or defocusing (Puttergil, 2000 in Banda, 2006), essentially follows similar steps. The field interviews and discussions listened to, transcribed, coded (if necessary), read at least twice to identify recurring issues, concepts or themes. Where possible, a computer-based programme, such ATLAS.ti. In the absence such software, as was the case with this study, the data are analysed manually. The verbal data are interpreted in line with the set objectives; emerging themes and deviations from the norm are noted and explained (Hamersley and Atkinson, 1983).

\section{Findings and Discussion}

\section{RLC Engender Infrastructure Development}

Interviews with two village chiefs, the RLC coordinators for MBC and Dzimwe Community revealed that RLCs had influence change in the Monkey Bay area. The sections below present abridged versions of the MSC narratives. 


\section{Rlcs Create Linkage between Village and Water Provider}

Chief Mwalembe, aged 70 years, keeps an update of his village assets and population. He knows, without referring to any notes that his village has a population of 4000 people, one primary school, one Mosque, one Anglican church and one catholic church, but no clinic. Although he does not attend any meetings, he is aware of what the Mwalembe Boys Radio Listening Club in his village discusses.

Due to the presence of the club, the chief claims, the village is aware of national political issues. He is also aware that the Icelandic Development Agency (ICEIDA) has rehabilitated, and built new potable water-points in his area. He is equally aware that the RLC has opened vegetable demonstration fields near each water-point to act as "research gardens" or "training schools" for the community.

"You can visit these training schools at Chimenya and Kachere if you have time”, he challenges the researcher.

Chief Mwalembe feels the RLC has been able to produce tangible results because its members are focused on developing their area. As such, RLC has united the village around common social issues. The chief's narrative is endorsed by the 35 year-old secretary of the Mwalembe Boys Radio Listening Club. It might sound funny that at 35 years some still considers himself a boy. "Boy" must be understood to refer to a middle aged man; a man who has passed the 18 birthday, but he feels youthful and ready to contribute to his communities' social and political development. Mchakulu (2007) quotes Isamah as describing such "boys" as "young people who are no longer children, but not yet adults, [and] who are expected to behave partly as children, partly as adults and partly as a unique age group" (Mchakulu, 2007: 254).

The "Boy" takes the researcher on a transect walk of the village. He points at one borehole and its adjacent research garden as the researcher and boasts:

"There are boreholes all over. Not only are these available here at Mwalembe, but there others at Maudzu, Mpale, Chindoyo, Masanche, Mang'umbi, Chilembwe, Kalumba... For every 20 households there is a clean source of water." 
The Mwalembe Boys RLC secretary explains that the club members have achieved great things for the community because they are committed to see live a better life their ancestors and parents.

To get more information about the waterpoints in the Mwalembe village, the researcher visits the Icelandic International Development Agency (ICEIDA) field office where he meets two senior operations officials who agree with Mwalembe Boys RLC secretary's testimony. They say ICEIDA has sunk numerous boreholes in the area, partly because the Dzimwe Community Radio station, the RLCs and the ICEIDA have effectively collaborated to spread public awareness messages on general sanitation, care for toilets, and water sources.

It is difficult to quantify the value of fresh water, but the long term benefits are clear Mwalembe is a village with little or no diarrhea and other water borne diseases; it is a village where women's troubled search for water has become history, and it is a village where every adult knows the causes of AIDS and how to avoid catching HIV. Mwalembe is a village is healthy and likely to contribute to its own development. That is social transformation by any definition. According to two other members of the Mwalembe Boys RLC, the club has also been involved in Youth and HIV prevention; Polygamy and HIV prevention; environmental protection; culture and HIV prevention, and education, youth and HIV.

\section{RLC Courts FAO to Establish Agricultural Scheme}

An in-depth interview with Chief Nsumbi reveals a catalogue of social changes attributed to the presence of a RLC in the area. The village chief claims that because of the RLC, his village has been reforested; most women have changed their promiscuous sexual behaviour because they have found alternative livelihood pathways; every household has at least a goat, curtsey of the Food and Agriculture Organisation (FAO), which came in when the RLC members asked for income generating activities, and he, too, is a beneficiary of the goat "pass-on” programme.

However, the chief quickly points point out that the success of the goat pass-on programme is also the village's curse. He says:

"There are more than 400 goats in this village. Where do they all graze? Conflicts have erupted between households and I preside over goat related 
issues daily", the village headman says, before asking: "What should I do? Ask people to dispose of the goats? Not at all. Doing so would take us backwards. But I have asked households to team up and find a shepherd for the goats".

Unlike cattle, goats are fast maturing, quickly reproducing and therefore economically viable. Apart from providing milk and meat for home consumption, goats can be sold whole at not less than US\$ 20.00 each. Quantitatively, therefore, Nsumbi village is worth US\$8,000 in goat assets alone. Additionally, fishing and irrigation farming still go on in the same village.

\section{RLC Coordinators Testify}

The Dzimwe Community Radio Station RLC coordinator agrees with both the Mwalembe Boys RLC and the Nsumbi village chief. She further reports that to due to RLC activities in Monkey Bay, the Ministry of Education built a primary school in the Kankhande area of Nakumba in 2005. Additionally, the bridges in the area were repaired to enable children attend classes throughout the year. World Vision Malawi and UNICEF provided boreholes in the Kankhande area and around the school. In the Nsumbi area, ICEIDA provided boreholes, introduced san-toilets, opened adult literacy centers and provided chicken for income generation. The FAO helped with the establishment of an irrigation scheme near Chikoko Bay in the Nsumbi Village. In the Balamanja area layer chicken were provided, but the business failed for lack of feed. At about the same time, Panos Southern Africa gave the Tigwirizane RLC money to produce HIV programmes. Instead, Tigwirizane RLC bought goats. In the same Balamanja area, ICEIDA introduced adult literacy schools, mostly for men, but the schools did not last.

The Dzimwe Community Radio RLC coordinator's narrative is validated by the coordinator of RLCs at the Malawi Broadcasting Corporation (MBC), which has been working with the Monkey Bay communities through its Development Broadcasting Unit since 1999. The MBC RLC coordinator reports:

"The women there (in Monkey Bay, Malawi) have been able to get loans from the international microcredit organization, FINCA and the Malawi Rural Finance Company (MRFC) to establish grocery shops. The women have also started chicken rearing businesses. They convinced the FAO to start an irrigation agriculture scheme. The road network has been rehabilitated. There is a junior primary school established 
in the area. All these developments have come about because of the RLCs and the 30minute programme we broadcast here at MBC, Mgwirizano Pachitukuko (Unity in Development) formerly called Amai pa Chitukuko (Women in Development) ’.

\section{RLCs Provide Relevant Content}

The RLCs have benefited the communities as much as they have benefited radio broadcasters. The Dzimwe Community Radio Station manager admits that development broadcasting is resource intensive and the RLCs have proved to be handy as sources of local content. The coordinator of RLCs at the MC added that availability of local through RLCs has cut down the production costs of development broadcasting.

\section{Factors that Make Rlcs Work}

Two Women's RLCs, Tipilire at Nsumbi, near Monkey Bay Trading Centre and Tigwirizane at Balamanja, some ten kilometers to the south of Monkey Bay were contacted for focus group discussions. Both clubs are located near the shores of Lake Malawi. Other than the two clubs are a study in contrast. While the people of Nsumbi village can easily access the lake, their Balamanja counterparts cannot as the entire lakeshore, except for a graveyard has been taken up by resorts owned by politicians and business people resident in Lilongwe, Blantyre and elsewhere. Nsumbi village is a typical Malawian village with homes of the relatively well-to-do existing side by side with those of the poor. Balamanja is different. It looks like an apartheid city with the rich living a 21 st century lifestyle while the poor live a typically third world life with no running water; sleep in huts with no iron roofing and use mats to protect their doorways. The two clubs are also different, emotionally. The members of Tipilire RLC can afford a smile, but the faces of their Balamanja counterparts tell a different tale.

\section{Unity of Purpose and Co-Capitalisation}

According to the Tipilire RLC treasurer was established in 1998 with encouragement from the Wildlife Society of Malawi (WESM), which had a field office in the area. Then it was a mere environmental club. Originally, the RLC aimed at helping the community to share knowledge on environmental protection and reforestation; to cultivate vegetables and make juices from locally available wild fruits; to create public awareness about the public ownership of natural resources, particularly the natural forests around the Monkey Bay area 
and to seek modern facilities and innovations that would contribute to community good health.

Originally, the club had 20 members of whom four were men. Later two men left the club. The Malawi Media Women's Association (MAMWA) through the Dzimwe Community Radio became interested in the already established club and encouraged the members to become a radio listening club. The club, like the seven other RLCs in the Monkey Bay area, has a recorder (donated by PSAf) for recording discussions and content to present in the programme and a radio set to listen to radio broadcasts and review their programmes. The RLC members meet twice a month to discuss issues, but three times a week to listen to and review the broadcasts. One of the members of Tipilire RLC reported that among others, the RLC has enabled women to speak out against gender violence, establish small businesses, and openly discuss HIV and AIDS. According to the RLC member:

"The goat pass-on programme started with 20 goats, but almost every household now has a goat kraal. We even have a local fertilizer revolving fund. We started it by contributing US\$10 each. We have no problem accessing farming inputs here."

With the assistance of the FAO, Tipilire RLC has established an irrigation project. According to the members interviewed, the FAO bought cement and gave them advice, but the local community did everything else including digging canals.

Unity of purpose and readiness to co-finance community development projects seem to be the main drivers of the success of Tipilire RLC.

\section{Tigwirizane RLC: Community Sees No Benefit from RLC}

The focus group discussions with six members of the Tigwirizane revealed that the RLC was established in 2001 by Dzimwe Community Radio as part of the PANOS Development Through Radio initiative. It is a typical women only club formed to empower the women of Balamanja to speak out and for the members to articulate the development needs of the Balamanja community. The membership has since dropped by $28 \%$ from the original 25 to 18. According to one member, men were invited to join the club, but they refused. 
The women do not hide their frustration and disappointment. One member explains:

"We asked for a junior primary school from the Malawi Social Action Fund (MASAF), currently known as Local Development Fund. But, nothing has happened. We were told later that our village did not make the required contribution.

Moderator: "Why didn't you contribute?"

Why should we contribute? [....] We asked for goats from OXFAM, which answered positively, but there has been no follow up as the person who was who was handling our issues went away."

Another says the club obtained 100 chicken, but 88 of them died essentially because the RLC members did not know how to care for "hybrid" chicken.

Another member recalled that in 2004 the club received US\$350 from PSAf, the same money the Dzimwe Community Radio RLC said was meant for an HIV radio programme, with which the club bought goats. As to how many goats the RLC has presently, one member gives this answer:

"They multiplied and four of them are still alive... er... we have also asked for a junior primary school, but we want the current MP to resign because he has failed us".

(Moderator): "How?"

"He is not assisting us. We asked PANOS for a sewing machine as our income generating activity. PANOS promised to assist, but nothing is forthcoming."

Tigwirizane's list of needs is endless. They RLC is pleading for money for business, fertilizers, and care for orphans. After talking to Tipilire and Tigwirizane RLC one sees the difference between a club that had a raison d'etre and another that was assembled by an exogenous agent. While Tipilire claims positive developments at personal and community levels, Tigwirizane fights for more help in exchange for little or no effort at all. Even development NGOs seem to have given up on this community if the ICEIDA process evaluation is anything to go by:

In other villages, as Balamanja shows, it must be admitted that, after a programme lasting several years, the results in terms of increased literacy have been very small, 
the developmental changes in the community have been insignificant, and the empowerment of women hard to measure (ICEIDA, 2008:80).

Attitude towards community work and lack of unity seem to be the problem at Balamanja. The community has failed to make good use of external financial and material support.

\section{Conclusion}

It is difficult for one to draw clear and generalisable conclusions from the above anecdotes, interviews and narratives. However, what comes out succinctly from the above verbal data is that, well used, RLCs have the potential to bring about infrastructure development because they conscientise the community to look into itself for solutions to local problems; empower community members politically and ideologically; promote local cultures and languages; act as a platform for the voiceless, and promote critical social change debates. The narratives also demonstrate that a Radio Listening Club will succeed if it is well organized, focused and prepared to co-finance development programmes. It seems that RLCs whose members are as dedicated and visionary as Tipilire RLC's are likely to succeed while those with members reliant on exogenous support will fail. Further, the narratives indicate that it would be hasty to attribute the successes of development projects to RLCs alone. For example, the boreholes in the Monkey Bay area are a result of RLC activities and the normal fulfillment of ICEIDA programme of action. However, a symbiotic relationship needs to exist between development agencies and communication for development projects such as RLCs. It is also clear that RLCs will only have impact if their content is used by radio stations. Thus, these successes of the RLCs in Monkey Bay are partly due to the dedication of the MBC and Dzimwe radio stations, which have also benefited, at least in terms of local content, from their involvement with the RLCs.

Since the RLCs seem to influence social change and development, the study recommends that all radio-based communication for development interventions should be accompanied by some form of RLC. The establishment of RLC, should however, be preceded by a community readiness assessment to ensure that resources are spent on communities that are willing to change. 


\section{References}

Banda, F.(2006). Radio Listening Clubs in Zambia and Malawi: Towards a Model of participatory Communication. Lusaka: Panos Southern Africa. Bell, J. (2007). Doing your Research Project: A guide for first time researcher in education, health and social science. London: Open University Press.

Bryman, A. and Teevan, J.J. (2005). Social Research Methods. Toronto: Oxford University Press.

Chimala, H. (2011). Winds of Change- HIV/Aids and Climate Change Programming on MBC Radio One. Paper presented at the $3^{\text {rd }}$ Farm Radio Symposium, 23-24, November, 2011, Malawi Institute of Management, Lilongwe, Malawi.

Creswell, J.W. (2003). Research Design. London: SAGE.

Figueroa, M.E., Kincaid, D.L., Rani, M. \& Lewis, G. (2002). Communication for Social Change: An Integrated Model for Measuring the Process and Its Outcomes. New York: Rockefeller Foundation.

Hamersley, M \& Atkinson, P. (1983). Ethnography: Principles in Practice. London: Routledge.

Danida. (2011). Cross-cutting Monitoring of the Civil Society Strategy: Inspirational Catalogue of Ideas. [Online]. Available: http://um.dk/da/ /media/UM/Danishsite/Documents/Danida/Samarbejde/Civil-org/Adm-retnlinjer/Tilskudsforvaltning/16\%20Bilag\%2011d\%20Catalogue\%20for\%20inspiration.a shx. (Accessed 22 April, 2013).

ICEIDA. (2008). The ICEIDA-Supported Reflect Programme in Monkey, Malawi: A Process Review.[Online]. Available: http://www.iceida.is/media/pdf/MALAWI_REPORT.PDF (Accessed 13 May, 2013).

Kvale, S. (1996). InterViews: An introduction to Qualitative Research Interviewing. London: SAGE.

Makowa, G. (2009). Mwana Alirenji Radio Magazine Turns Malawian Farmers into researchers, Innovators and food sufficiency (sic). Brussels: CTA [ Online]. Available: www.annualseminar2009.cta.int. (Accessed 23 May, 2013).

Manyozo, L. (2005). Rural radio and the Promotion of People-centred Development in Africa: Radio Listening Clubs and Community Development in Malawi. [Online]. Available: 
http://www.codesria.org/Links/conferences/general_assembly11/papers/manyozo.pdf. (Accessed 11 August, 2010).

Manyozo, L. (2012). People's Radio: Communicating Change Across Africa. Penang: Southbound.

Mchakulu, J.E. (2007). Youth Participation in Radio Listening Clubs in Malawi. Journal of Southern African Studies, 33(2): 251-265.

Moyo, M. (1991). Development Through Radio. Community Development Journal, 26 (3): 227-232.

Mouton, J. (1996). Theory, Metatheory and Methodology in Development Studies in Reconstruction, Development and People. Johannesburg: International Thomson Publishing.

PSAf. (n.d). Methodologies. [Online]. Available: http://www.panos.org.zm/?page_id=17. (Accessed 11 February, 2014).

PSAf. (2003). Development Through Radio: A Guide to Setting Up Radio Listening Clubs. Lusaka: Panos Southern Africa.

PSAf. (2013). Radio Platform for Community Development Project. Unpublished Final Narrative Report submitted to OSISA. Lusaka: Panos Southern Africa.

Rasmussen, F. (2009). A review of ADRA's project: “Women in Post-Conflict Situations: Sharing Stories that may lead to Change. Regional project in Burundi, East DRC, and Rwanda." Copenhagen: ADRA Denmark.

Strelitz, L. (2002). Where the Global Meets the Local: South African Youths and their Experience of Global Media. PhD Thesis, Rhodes University, South Africa.[Online] http://eprints.ru.ac.za/20/2/strelitz-phd.pdf . (Accessed 11 April, 2014)

Uladi, R.( 2011). The Role of Listening Clubs in the Development of Malawian Communities: A case Study of Kanthu N'khama Program of the Malawi Broadcasting Corporation (MBC). Unpublished Bachelor of Arts in Journalism Dissertation, the Polytechnic, University of Malawi.

UNESCO. 2010. Establishment of the Usisya Community Radio Station. [Online]. Available http://www.unesco-ci.org/ipdcprojects/content/establishment-usisya-communityradio-station. (Accessed 13 March, 2014).

Warnock, K.(2001). Empowerment of Women - Development Through Radio (DTR) Radio Listening Clubs, Zambia: Impact Evaluation Report. [Online]. Available.:http://www.comminit.com/africa/content/empowerment-women- 
development-through-radio-dtr-radio-listening-clubs-zambia-impact-eval. (Accessed 12 March, 2013).

Yin, R. (1994). Case Study Research: Design and Methods. Thousand Oaks: SAGE. 